\title{
Improving Self-Regulated Learning Style amongst Students
}

\author{
Hamilton-Ekeke, Joy-Telu \\ Department of Teacher Education, Niger Delta University, Wilberforce Island, Bayelsa State, Nigeria
}

Email address:

joytelu@yahoo.com (Joy-Telu)

\section{To cite this article:}

Hamilton-Ekeke, Joy-Telu. Improving Self-Regulated Learning Style Amongst Students. International Journal of Secondary Education. Special Issue: Teaching Methods and Learning Styles in Education. Vol. 3, No. 6-1, 2015, pp. 72-76. doi: 10.11648/j.ijsedu.s.2015030601.12

\begin{abstract}
Learning is a goal directed act, acquiring new, or modifying and reinforcing existing knowledge, behaviours, skills, values, preferences and may involve synthesizing different types of information. Learning may be viewed as a concept and like all other concepts; it lacks a generally accepted definition. However, there appear to be a consensus that it is a relatively permanent change in behaviour as a result of practice or experience. The purpose of education is not merely to enable students to accumulate facts. A major goal is that by the time students finish school; they should be able to solve problems that will enable them to be happy and successful in life and to contribute to society. To achieve this goal, students need to develop high order thinking skills through self-regulation of learning. Self-regulated learning is learning that is guided by metacognition (thinking about one's thinking), strategic action (planning, monitoring, and evaluating personal progress against a standard), and motivation to learn. Metacognition was regarded as a valuable term because it emphasized how the "self' was the agent in establishing learning goals and tactics and how each individual's perceptions of the self and task influenced the quality of learning that ensued.
\end{abstract}

Keywords: Regulated Learning Style, Method of Teaching, Student Achievement, Individualized Learning, Cognitive Skills

\section{Background of Self-Regulated Learning}

The emphasis on self-regulated learning in education began as an outgrowth of behaviourally oriented research on self-control in which individuals learned ways to reduce dysfunctional behaviours such as impulsive or disruptive actions. Behavioural researchers (Mace, Belfiore, and Hutchinson, 2001) stress self- regulating processes such as self-monitoring (self-observation and self-recording of one's own behaviours), self-instruction (rules or strategic steps that one applies and often verbalizes during a task), selfevaluation (comparing some aspects of one's behaviours with standards), self-correction (correcting one's behaviours to better match standards), and self-reinforcement (rewarding oneself with reinforces such as points or free time when behaviour meet or exceed standards).

An issue with behavioural theories is that because they do not consider learners' internal states such as thoughts, beliefs, and emotions, they offer incomplete explanations of learning. Against this backdrop cognitive theories of learning began their ascendance in the 1960s and soon became the dominant focus of human learning. But researchers often found that cognitive skills and abilities did not fully account for students' learning, which suggested that other factors such as motivation and self-regulation were important (Zimmerman, 2001). These findings led to the emergence of cognitive theories of self-regulated learning.

\section{Theories of Self-Regulated Learning}

Cognitive theories of self-regulated learning differ in many ways but share some common features (Zimmerman, 2001). One common feature is an emphasis on learners being proactive and exerting control on their learning processes and environments. Self-regulated learners do not passively take in information but rather proactively develop their skills and strategies.

Cognitive theories also assume that self-regulated learning is a cyclical process in which learners set goals, implement strategies, monitor their learning progress, and modify their strategies when they believe they are not effective.

A third common feature is an emphasis on motivation. Self-regulated learning does not occur automatically; rather, students approach learning with goals and the extent to which they self-regulate depends on motivational factors such as their commitment to their goals, their beliefs about the likely 
outcomes of their actions, and their self-efficacy, or personal beliefs about their capabilities to learn or perform actions at designated levels. Although, there are various cognitive selfregulated learning theories, three that have been applied extensively to school learning are information processing, social constructivist, and social cognitive theories. Information processing theory stresses cognitive functions such as attending to, perceiving, storing, and transforming information. For example, Winne and Hadwin (1998) postulated that self-regulated learning comprises four phases: defining the task, setting goals and planning how to reach them, enacting tactics, and adapting metacognition (knowing about knowing).

Initially, learners process information about the conditions that characterize the task to clearly define it. Sources of information include task conditions (task information that learners interpret based on the environment such as a teacher's directions) and cognitive conditions that learners retrieve from long-term memory such as how they did on prior tasks and motivational information (perceived competence). In the second phase learners set a goal and a plan for attaining it to include the learning strategies they will use.

During the third phase learners apply their strategies, and in the fourth phase they adapt their plans and strategies based on self-evaluations of their success (this phase is optional if no adaptation is needed). Within each phase, cognitive information processing constructs new information or information products. Information processing works on existing information and includes processes characterized by the acronym SMART: Searching, Monitoring, Assembling, Rehearsing, and Translating. While working on a task, students fill in slots in a script that includes conditions, operations, products, evaluations, and standards. Information processing outcomes are judged against standards and these evaluations (e.g. progress is on target or too low) are used to bring new conditions to bear on students' learning activities.

Vygotsky's theory of development provides a social constructivist account of self-regulation. Vygotsky (1962) believed that people and their cultural environments constitute an interacting social system. Through their communications and actions people in children's environments teach children tools (e.g. language, symbols) needed for developing competence. By using these tools within the social system, learners develop higher-level cognitive functions such as problem solving and selfregulation.

Self-regulated learning includes the coordination of such mental processes as memory, planning, synthesis, and evaluation. These coordinated processes do not operate independently of the context in which they are formed. A student's self-regulated learning processes reflect those that are valued and taught in the culture of the student's home and school.

Vygotsky believed that people learn to self-regulate through control of their own actions. The primary mechanisms affecting self-regulation are language and the zone of proximal development (ZPD) (Hamilton-Ekeke, 2008), or the amount of learning possible by a student given the proper instructional conditions. Initially children's actions are directed by the language (speech) of others but children gradually internalize this self-directing language and use it to self-regulate. Through interactions with adults in the ZPD children make the transition from behaviours regulated by others to behaviours regulated by themselves, or selfregulated learning.

Bandura's social cognitive theory posits that human functioning results from reciprocal interactions among personal factors (cognitions, emotions), behaviours, and environmental conditions. Self-regulated learning fits well with this idea of reciprocal interactions because personal factors, behaviours, and environmental conditions change during learning and must be monitored. Such self-monitoring can lead to additional changes in students' strategies, cognitions, affects, and behaviours.

This process is reflected in Zimmerman's (2001) threephase self-regulated learning model comprising forethought, performance/volitional control, and self- reflection. The forethought phase precedes performance and refers to processes that set the stage for action. The performance/volitional control phase includes processes that occur during learning and that affect motivation and action. During the self-reflection phase, learners mentally review their performances and determine whether changes in behaviours or strategies are needed.

Various self-regulatory components come into play during the different phases. Two processes active throughout the model are goals and self-efficacy. In the forethought phase, learners set goals and hold a sense of self-efficacy for attaining them. During the performance phase they implement learning strategies and cognitively compare their performances with their goals to determine progress. Their self-efficacy is sustained when they believe that they are making goal progress. During self-reflection learners determine whether their present strategy is effective. If they feel self-efficacious for succeeding but believe that their present strategy is not working well enough, they may alter their strategy such as by working harder, persisting longer, deciding to use a different method, or seeking help from others. These self-regulatory processes promote learning, motivation, and self-efficacy.

\section{Development of Self-Regulated Learning}

The self-regulated learning processes discussed in the preceding section do not appear automatically in learners. Rather, students become more proficient self- regulators as a function of cognitive development and learning. The development of self-regulation depends heavily on the use of self-regulatory or private speech (speech that is non-socially communicative). According to Kopp (1999), increasing selfregulation involves a transition from responding to the 
commands of others to the use of speech and other cognitive tools to plan, monitor, and direct one's activities. Young children's actions are directed by adults. The meaning of actions depends on both the context and the tools (language, symbols) used to describe the actions. Through interactions with adults in the $\mathrm{ZPD}$, children make the transition from behaviours regulated by others to behaviours regulated by themselves. This transition occurs as children develop the capability for using private speech to direct their actions. Such speech — which often may be talking aloud eventually becomes internalized. The internalization of selfregulatory speech does not imply the absence of adult influence. Children's private speech may heavily reflect the directive speech of key adults (parents, teachers).

Research has identified other developmental changes, between primary and secondary children increase their use of planning, sequencing, and goal-setting, academic studying also undergoes changes. Meece (2002) noted that younger children equate studying with rereading material, whereas older students make greater use of note taking and underlining. Younger children also are less capable of monitoring their comprehension. Older children are better able to determine inconsistencies in text and when they find them they act to resolve them such as by rereading the passage to ensure that they read it accurately or by reading the broader passage to better determine the context.

Thus, improvements in self-regulated learning involve cognitive development and learning. As children become older they are better able to cognitively engage in such selfregulatory activities as planning, goal setting, monitoring comprehension, evaluating progress, and adjusting strategies as needed. But teaching also is important because students can learn to be better self-regulators.

\section{Research on Improving Self- Regulation Skills}

As discussed by Schunk and Ertmer (2001), much educational research shows that children, adolescents, and adults can be taught self-regulated learning skills, which their use of these skills improves learning, and that skills can maintain themselves over time and generalize to new learning settings. For example, teaching students to use goal setting can improve their self-regulated learning. There are different distinctions among goals, but one is between a process goal (what skill or strategy students are attempting to learn) and an outcome goal (the intended performance). In algebra a student may be trying to learn how to use the binomial theorem (process goal) or trying to finish a problem set (outcome goal). Researchers (Meece, 2002; Schunk and Ertmer, 2001) have found that focusing students' attention on process goals - especially in the early stages of learning improves self-regulated learning better than focusing on outcome goals.

However, Zimmerman and Kitsantas (2000) found benefits from shifting from process to outcome goals. Secondary school students were taught a writing revision strategy. Students' received a process goal (following steps in the strategy), an outcome goal (number of words in sentences), or initially a process goal but then were advised to shift to an outcome goal. Learners who changed goals as their revision skills developed demonstrated higher self-efficacy skill than students who pursued either the process or the outcome goal.

Self-monitoring and perceptions of progress are key selfregulated learning processes. Researchers (Schunk and Swartz, 2002) have found that students can be taught selfmonitoring skills and that giving them feedback on their learning progress improves their use of self-regulatory skills. Schunk and Swartz (2002) found that providing students with a process goal of learning to use a writing strategy and feedback that linked strategy use with improved writing performance led to the highest use of a writing strategy and that this strategy usage maintained itself over time and generalized to writing tasks on which students had received no instruction.

Self-evaluations of progress help students focus on selfregulation processes and can raise their motivation and selfefficacy for continuing to improve. Research shows that allowing students to periodically evaluate their learning capabilities raises their self-efficacy, motivation to selfregulate, and use of self-regulated learning strategies. A particularly effective approach is to give students a learning process goal (learn to use a strategy to solve problems) and allow them to self- evaluate their capabilities for using the strategy successfully.

There are formal programs designed to improve students' self-regulation skills. Weinstein, Husman, and Dierking (2001) described a university course in strategic learning that teaches students to use several steps in working on academic material: set a goal, reflect on the task and one's personal resources, develop a plan, select potential strategies, implement strategies, monitor and evaluate the strategies and one's progress, modify strategies as needed, and evaluate the outcomes to determine if this approach should continue to be used. Prior to the course students complete the Learning and Study Strategies Inventory, and instructors use this information to help students improve their skills, motivation, self-regulation, and academic environment.

\section{Effects of Self-Regulated Learning}

There has been a drastic change in the concept of educational psychology in the last three decades, so much so that nowadays, self-regulated learning has become a major focus of research. Although the term 'self-regulation' is synonymised with words such as self-control, self-discipline and self-direction, various definitions exist for the same which have arisen from the different theoretical concepts existing on self-regulated learning. Self-regulated learning is defined as the capability of active participation in the learning process from the view point of meta-cognition, motivation and behaviour (Zimmerman 1990).

Self-regulated learners have skills from the perspective of 
meta-cognitive knowledge and know how to direct their mental processes in the direction of achievement and personal goals. They embark on planning, self-inspection, self- controlling and self-evaluation in the different stages of their learning. From the standpoint of motivation, this kind of learning greatly helps in the development of suitable adaptive beliefs and views in the field of education, especially in things like, preference in doing school work, effort, perseverance etc., and results in the fact that the individual feels worthy, strong and independent. Further, these learners have the ability to select, establish and create efficient learning environments (Pintrich 2000, Schunk and Ertmer 2000). Moreover, self-regulated learners have different cognitive strategies like repetition and rehearsal and elaboration and organization which they can easily use for better comprehension and improvement of memory in carrying out their school work.

\section{Models of Self-Regulated Learning}

There are different models for self-regulated learning. One of the models is the Pintrich model (2000), where four phases are identified, these include different regulatory processes: planning, self-monitoring, control and evaluation. Each of these phases in turn incorporates self-regulated processes linked to specific dimensions: cognitive, motivational and affective, behavioural and contextual. During the initial years of cognitive change in educational psychology, i.e. in the 70s and $80 \mathrm{~s}$, research was mainly focused on cognitive variables, such as, processing information, cognitive styles, learning strategies, prior knowledge and thinking processes. In the 1980s and 1990s, extensive research was done in the field of motivational variables - self-concept, beliefs, attributions, aims, etc. On the whole, it can be said that a large number of studies in the field of educational psychology have been undergone to see how self-regulated learning can result in higher levels of educational achievement in students and facilitate learning (Pintrich 2000, Zimmerman \& Martinez, Pons 1986, 1980). Some researchers of educational psychology in the field of self-regulated learning, like Boakaertz (2005) etc., stand united on this point that although much research has been done in recent years on self-regulated learning especially on learning styles and the cognitive aspects of learning processes less attention has been paid to the role of self-regulated learning as an intricate and strong construct in other themes, like motivation and emotional processes.

In other words, most research has been limited to metacognitive control systems and little study has been done on other control systems, such as, motivational, action, emotional controls and other topics related to system of self and objective behaviour (Rozendaal, Minneart and Boakaertz, 2005). With regards to self-regulated learning, Shonkoff and Philips (2000) have defined self-regulation as the capability of the child to gain a control over physical actions, emotional management and maintenance of attention and concentration; and they believe the development of self- regulation is the basis for early childhood growth and is visible in all aspects of behaviour.

Bandura (2005) also believes that self-regulation is correlated to a growth in health, and is of special importance in health control. Attribution styles are distinguished in the way an individual habitually conceptualizes the cause of events. According to Cheng and Furnham (2001), in the last two decades ample evidence has been accrued to show the direct relationship between attribution styles and mental health such as depression, anxiety and depression, self esteem and shameless. The studies show depressive patients emerge internal, global, and stable attributions for negative events although paranoid patients show this attribution for positive events.

Recent research in the field of self-regulated learning has also emphasized the importance of the role of attributions as motivational variables of self-regulated learning and negative attribution styles are related to lower grades, not seeking help, vague goals, weak usage of learning strategies and lower achievement expectations. Moreover, students can modify these attributes by becoming aware of them and getting guidance from experienced teachers for the same. Zimmerman (2000) believes that in the stage of selfreflection, self-regulated learners interpret attributes, usually positive ones, for judging themselves in the field of academic tasks. These individuals have the tendency to attribute failure to reform able factors and success to personal merit. Shahrara and Soleimannegad's (2002) research shows that a meaningfully positive correlation exists between the selfregulation of students and their internal locus of control. One of the effective approaches for modifying pessimistic attributes is through training. Self-regulated learning, that has become one of the axes of educational activities, is a popular subject in the field of the educational psychology. Research (Shahrara and Soleimannegad, 2002) has shown that school students function increased after they had been taught selfregulated learning strategies, and students who had been taught self-regulated learning strategies became more selfregulated.

\section{Conclusion and Educational Implications of Self-Regulated Learning}

The preceding research makes clear the connection between effective self-regulation and gains in students' learning and achievement. Research findings also suggest ways to help students improve their self-regulated learning skills. One suggestion is that, although students may discover effective self-regulated learning strategies on their own, they benefit from sound instruction and models that explain and demonstrate strategies. This does not imply that strategy instruction programs must be formally structured, but some guidance to students is important especially in the early stages of learning. As students become more proficient they are better able to construct effective strategies on their own 
and, as Zimmerman and Kitsantas (2000) found, pursue outcome rather than learning process goals.

A second point is that self-regulation should be taught in conjunction with an academic subject and not separately. Students benefit from seeing how they can use what they learn. Many self-regulation strategies are generic and can be applied to different content, but their implementation typically will vary depending on the content area. Thus, selfmonitoring is a general strategy but what students selfmonitor will vary depending whether they are reading passages in text, writing essays, or solving problems in geometry. When general strategies are taught it is important also to show students how the strategy can be adapted for use with other content.

Students should be taught how to evaluate their learning progress and given opportunities to do so. Typically in school, students have their learning evaluated for them by teachers. But self-regulation is a cyclical process in which students self-regulate, check their progress, and adjust their approach as needed. Students need opportunities for selfevaluation because they may not do it automatically and it affects their motivation and self-regulated learning.

Developmental factors must be taken into account in teaching students to be better self-regulated learners. Selfmonitoring is best kept simple for young children, such as by having them use a check list or count how many problems they have completed. With development, students can implement more elaborate self- regulation strategies; however, they are apt to benefit from instruction showing how to evaluate progress in areas where progress may be difficult to assess, such as writing improvement or reading comprehension.

Motivational variables also should be included in selfregulation programs. Developing effective self-regulation strategies takes time and effort, and students may not be motivated to self-regulate unless they see benefits compared with their usual approaches. They also may not feel selfefficacious about improving their self-regulation. Providing students with progress feedback linking strategy use with improved performance can raise their self-efficacy and motivation and enhance their self-evaluations of progress. School learning typically is focused on academic content. Self-regulated learning skills do not develop automatically, but these skills will benefit students for life-long learning. Therefore, it behoves teachers and parents to help students develop their self-regulatory competencies and encourage them to practice using them in all facets of their lives.

\section{References}

[1] Bandura A. (1986) Social foundations of though and action: A social cognitive theory. Eaglewood Cliffs, NJ: Prentice Hall.

[2] Bandura A. (2005), The primacy of self-regulation in health promotion. Applied Psychology: An international review. 54(2), 245-254.

[3] Hamilton-Ekeke, J-T. (2008) The effect of a social constructivist theory of teaching/learning on both conceptual understanding and practical application of dietary knowledge, An unpublished $\mathrm{PhD}$ thesis, University of Wales, Aberystwyth, United Kingdom

[4] Kopp C.B. (1999). Antecedents of self regulation: A developmental perspective. Developmental Psychology. 18, 199-214.

[5] Meece J.L. (2002) child adolescent development for educators ( $2^{\text {nd }}$ ed.) Boston: McGraw-Hill

[6] Pintrich, P.R. (2000). The role of motivation in promoting and sustaining self-regulated learning. International Journal of Educational Research. 31, 459-470.

[7] Rozendaal, J.S; Minaert A; and Boekaerts (2005).The influence of teacher perceived administration of self-regulated learning on students motivation and information . Learning and Insruction.15, 141-160.

[8] Schunk D.H. and Swartz C.W. (2002): Goals and progress feedback: Effects on self-efficacy and writing achievement. Contemporary Educational Psychology, 18, 337-354.

[9] Schunk D.H. \& Ertmer P.A. (2000), Self-regulated learning and academic learning: Self-efficacy enhancing interventions. In M. Bo

[10] Schunk D.H. \& Zimmerman B.J. (1997) Social origin of Self Regulatory competence. Educational Psychologist, 32, 195208 .

[11] Shahrara, M., Solaimannegad, A. (2002). Relationship between locus of control, self-regulation and school achievement. Journal of psychology, 2, 34-56.

[12] Shonkoff J. \& Phillips D. Eds. (2000). from neurons to neighbourhoods: The science of early childhood development. A report of the National Research Council. Washington, DC: National Academies Press.

[13] Vygotsky L. (1962). Though and language. Cambridge, MA: MIT Press.

[14] Weinstein, C. E., Husman, J., \& Dierking, D. R. (2001). Selfregulation interventions with a focus on learning strategies. In M. Boekaerts, P. R. Pintrich, \& M. Zeidner (Eds.), Handbook of self-regulation (pp. 727-747). San Diego, CA: Academic Press.

[15] Winne P.H. and Hadwin A.F. (1998) Studying as selfregulated learning. In D.J. Hacker J. Dunlosky \& A.C. Greasser (Eds). Metacognition in educational theory and practice (pp. 277-304) Hillsdale, NJ: Erlbaum

[16] Zimmerman B.J. and Kitsantas A. (2000) Acquiring writing revision skill: Shifting from process to outcome selfregulatory goals. Journal of Educational Psychology, 91,241250 .

[17] Zimmerman, B J. \& Martinez-Pons, M. (1998). Development of a structured interview for assessing students' use of self regulated learning strategies. American Educational Research Journal. 23, 614-628.

[18] Zimmerman B.J. (2001), Theories of Self regulated learning and academic achievement: An overview and analysis. B.J. Zimmerman \& D.H. Schunk (Eds), Self regulated learning and academic achievement: Theoretical Perspectives $\left(2^{\text {nd }}\right.$ ed. $p$. 39-65) Mahwah NJ: Eribaum. 